\title{
Uma proposta de diálogo entre a Psicologia Social de Silvia Lane e a Análise do Comportamento
}

\section{A dialogue proposal between Silvia Lane's Social Psychology and Behavior Analysis}

\section{Una propuesta para el diálogo entre la Psicología Social Silvia Lane y Análisis dela Conducta}

\author{
Henrique Valle Belo Ribeiro Angelo', Enzo Banti Bissoli²
} [1] UNIP/PUC-SP [2] FMU / PUC-SP I Título abreviado: Análise do Comportamento e Psicologia Social I Endereço para correspondência: Rua Irmão Odilon
Diniz, 82 I Email: hvbrangelo@gmail.com I DOI: 10.18761/pac.2016.008

Resumo: Esse ensaio discute possibilidades de diálogo entre a Psicologia Social de Silvia Lane e a Análise do Comportamento. O diálogo terá três eixos centrais: a delimitação de um objeto de estudo, a noção de transformação social e o método de estudo. A partir desses eixos serão abordados pressupostos da Psicologia Social de Lane, bem como a influência do pensamento skinneriano sobre o pensamento de Lane, além disso, serão apontadas e debatidas algumas críticas da autora sobre a Análise do Comportamento de Skinner. Duas propostas de transformação social encontradas na Análise do Comportamento foram discutidas ao lado das propostas de Lane. O método de estudo também é discutido e a pesquisa-ação proposta por Lane é apresentada ao lado de métodos que a Análise do Comportamento tem utilizado para estudar fenenômenos sociais.

Palavras-chave: Silvia Lane, Transformação social, Fenômenos Sociais, Psicologia Social.

\begin{abstract}
This essay discusses possibilities of dialogue between Silvia Lane's Social Psychology and Behavior Analysis. The dialogue rests in three central themes: the definition of subject matter, the notion of social transformation and the method of study. From these axes, it will be addressed assumptions of Lane's Social Psychology, and the influence of Skinner's thought upon the Lane's, moreover, it will be identified and discussed some criticism of Lane upon Skinner's Behavior Analysis. Two proposals for social transformation found in the behavior analysis were discussed alongside Lane proposals. The study method is also discussed and the action research proposed by Lane is presented beside methods that behavior analysis uses to study social phenomena.
\end{abstract}

Keywords: Silvia Lane, Social change, behavior analyst practices, research methods in Behavior Analysis 
Resumen: Este ensayo discute las posibilidades de diálogo entre la Psicología Social de Silvia Lane y el Análisis dela Conducta. El diálogo tiene tres temas centrales: la definición de lo objeto de estudio, la noción de transformación social y el método de estudio. A partir de estos ejes, se abordarán los supuestos de la Psicología Social de Lane, y la influencia del pensamiento de Skinner sobre el de Lane, además, se identificará y discutirá algunas críticas de Lane a Análisis de la Conducta de Skinner. Dos propuestas de transformación social encontradas en el Análisis dela Conducta fueron discutidas junto con las propuestas de Lane. El método de estudio también se discute y la investigación de acción propuesta por Lane se presenta junto a los métodos que Análisis dela Conducta utiliza para estudiar los fenómenos sociales.

Palabras-clave: Silvia Lane, transformación social, fenómenos sociales, psicología social 
No Brasil, muitos psicólogos sociais têm trabalhado com análises de sistemas sociais e têm apontado a transformação social (a transformação das práticas de uma sociedade com o objetivo de diminuir desigualdades, como, a opressão proveniente de uma classe social dominante) como um objeto da Psicologia (Lane, 1981, 1984, 1996; Rosa \& Andriani, 2002; Sawaia, 2014). No entanto, a Psicologia Social não é a única a apresentar uma teoria que possibilite transformações sociais, muitos analistas do comportamento têm demonstrado uma preocupação com questões sociais (Andery, 1993; Fink, 2014; Glenn, 1986; Guerin, 1992b, 2001; Malott \& Glenn, 2006; Skinner, 1953, 1969, 1971, 1974, 1982, 1989; Wolf, 1978) e alguns mais especificamente com a transformação social (Glenn, 1991, 2004; Holland, 1978a; Skinner, 1948; 1953). Este ensaio pretende propor um caminho para realizar uma interface entre a proposta de Psicologia Social de Silvia Lane e Análise do Comportamento por meio de obras de diferentes autores que discorram sobre temas relacionados com a proposta de Lane.

\section{Diálogos anteriores entre algumas propostas de Psicologia Social e a Analise do Comportamento}

Guerin (1992a) apontou que: "Mesmo uma olhada superficial nos livros texto ou a maior parte dos manuscritos de Psicologia Social revelará que a Análise do Comportamento tem tido pouquíssimo ou nenhum impacto sobre a Psicologia Social" (p. 589). O autor diz respeito à Psicologia Social publicada em língua inglesa, principalmente à Psicologia Social norte-americana, embora essa afirmação pareça, à primeira vista, válida também na América Latina. Por exemplo, Martin-Baró (1990), um dos mais citados psicólogos sociais latino-americanos, pareceu reconhecer o papel da Análise do Comportamento no sistema teórico que propunha: "É importante enfatizar que esta visão da psicologia não descarta a Análise do Comportamento" (p. 15). Mas no mesmo parágrafo o autor apresentou uma visão equivocada do conceito de aprendizagem para a Análise do Comportamento: “(...) aprender não é somente elaborar e reforçar uma sequência de estímulos e respostas, mas sobretudo estruturar uma forma de relação da pessoa com seu meio, configurar um mundo onde o indivíduo ocupa um lugar e materializa seus interesses sociais" (p. 15).

Kunkel (1997) fez algumas ressalvas ao se estabelecer um diálogo entre Psicologia Social (norte-americana) e Análise do Comportamento: (a) seus métodos de pesquisa são diferentes, e (b) os tipos de fenômenos estudados são diferentes, a primeira tem como foco atitudes e crenças, enquanto a segunda tem como foco respostas mais simples e pouco abrangentes. $\mathrm{O}$ autor propõe, a partir da análise dos métodos utilizados por psicólogos sociais norte-americanos, uma mudança procedimental em pesquisas com humanos na Análise do Comportamento. Sugere que os analistas do comportamento passem a entrevistar os participantes a fim de obter informações acerca da história prévia do participante no que diz respeito: (a) às explicações que o participante elabora acerca de respostas e consequências; (b) à natureza da consequência e probabilidades de ocorrência e; (c) à distribuição temporal de consequências ao longo da vida do participante.

Outros diálogos foram propostos, para citar alguns: Guerin (1992b) fez uma leitura comportamental das noções de representação social de Serge Moscovici e Kenneth Gergen (dois importantes psicólogos sociais); Lana (1994) propôs a utilização do método de história social para identificação do repertório comportamental de uma pessoa e; Blackman (1991) propôs um diálogo entre as ideias de B. F. Skinner (Análise do Comportamento), G. H. Mead (Sociologia) e L. S. Vygostky (Psicologia Sócio-histórica).

Tendo em vista o objetivo de propor uma interface entre a Psicologia Social de Silvia T. M. Lane, um dos mais importantes expoentes da Psicologia Social brasileira e a Análise do Comportamento, será apresentada, a seguir, as principais concepções da autora juntamente com as possibilidades de interface das mesmas com as concepções analítico-comportamentais. 


\section{Concepções da Psicologia Social de Silvia Lane e interfaces com B. F. Skinner}

Silvia Lane propõe que a Psicologia Social pode ser um meio para realizar transformações em nossa sociedade, além de uma forma de produção de conhecimento sobre o ser humano. Essa transformação social levaria as pessoas a romperem com práticas sociais que favoreçam a desigualdade (Lane, 1981,1984). Essa desigualdade estaria diretamente relacionada, por exemplo, com o sofrimento psicológico dos indivíduos.

De acordo com Lane (1984) a produção de conhecimento sobre o ser humano envolve, necessariamente, diálogo e contribuição entre áreas do conhecimento científico. Para Lane o intercâmbio entre áreas possibilita que essas se complementem, como descrito no trecho abaixo:

Esta análise das categorias fundamentais para compreensão do ser humano nos leva à constatação da impossibilidade de delimitarmos conhecimentos em áreas estanques que comporiam o conjunto das ciências humanas. Psicologia, sociologia, antropologia, economia, história, pedagogia, linguística, são enfoques a partir dos quais todas as áreas contribuem para o conhecimento profundo e concreto do ser humano. Suas fronteiras devem ser necessariamente permeáveis, ampliando o conhecimento, seja do indivíduo, do grupo, da sociedade e da produção de sua existência material e concreta (Lane, 1984, p. 18).

Entende-se pelo trecho acima que as áreas que produzem conhecimento sobre o indivíduo, seus grupos, sociedades, entre outros, possibilitam que se conheça diversos aspectos relacionados aos seres humanos e que um diálogo poderia favorecer e ampliar a compreensão acerca das influências que participam da construção do ser humano. Quando a autora aponta o enfoque de sua proposta de Psicologia Social, é possível identificar que, de fato, existe a possibilidade de diálogo com a Análise do Comportamento:
O enfoque da Psicologia Social é estudar o comportamento de indivíduos no que ele é influenciado socialmente. E isto acontece desde o momento em que nascemos, ou mesmo antes do nascimento, enquanto condições históricas que deram origem a uma família, a qual convive com certas pessoas, que sobrevivem trabalhando em determinadas atividades, as quais já influenciam na maneira de encarar e cuidar da gravidez e no que significa ter um filho. (Lane, 1981, p.8-9)

No trecho acima, ao definir seu objeto de estudo como comportamento e colocar o foco nos processos pelos quais o meio social pode influencia-lo, Lane apresenta uma noção de que o meio social, ou o ambiente formado por outras pessoas, será responsável pela formação de um indivíduo, pelos comportamentos que tornar-se-ão característicos daquele indivíduo em sua história singular. Alguns analistas do comportamento também trabalharam com a noção de que grande parte do repertório comportamental é formada a partir da história de relações sociais (Guerin, 2001; Tourinho, 2009; Skinner, 1971). Guerin (2001) afirmou: "Mesmo dentro de uma mesma sociedade, as atividades que realizamos são construídas ou providas, em primeiro lugar, por outras pessoas, mesmo as atividades que realizamos sozinhos" (p. 411).

No trecho de Tourinho (2009), a seguir, apesar do foco ser a construção das relações comportamentais que possibilitam a concepção da individualidade, fica clara a influência das relações sociais:

$\mathrm{Na}$ medida em que vão se dissociando as consequências que mantêm o comportamento de cada um (que cada um vai sendo mais diferente de todos os demais porque suas relações com o mundo são cada vez mais particularizadas) e na medida em que isso acontece em um contexto de relações de dependência interpessoal indiretas muito complexas, mais e mais autocontrole vai sendo exigido do indivíduo (p. 175).

Nos trechos de Guerin (2001) e Tourinho (2009), fica clara a construção do repertório comportamental a partir das relações sociais, o que está diretamente ligada à noção de indivíduo. Além des- 
ses autores, Skinner (1971), também reconheceu o papel das relações sociais para a construção de repertórios comportamentais:

Uma criança nasce membro da espécie humana, com um arcabouço genético que demonstra muitos aspectos idiossincráticos, e ela começa imediatamente a adquirir um repertório de comportamento sob contingências de reforçamento as quais ele é exposto como um indivíduo. A maioria dessas contingências é arranjada por outras pessoas. (p.127)

Ainda que a semelhança seja visível no que diz respeito à construção social do indivíduo, existe uma diferença nos trechos de Skinner e Lane citados: Skinner (1971) afirma que a criança começa a sofrer efeitos de um ambiente "imediatamente" e Lane (1981) aponta que essa influência acontece "mesmo antes do nascimento". Isso parece ocorrer devido à ênfase de Skinner (1971), nesse trecho, ao indivíduo que passará a estar exposto ao ambiente, enquanto Lane (1981) deu ênfase ao processo histórico que constrói o ambiente social, que influencia inclusive a concepção de novos organismos da espécie humana, por exemplo, definindo práticas a serem assumidas na gestação ou para recém-nascidos. A ênfase na construção desse ambiente social, aparecerá em outros momentos da obra de Skinner (e.g. 1981; 1982; 1989), ao longo da maior parte de sua obra, a ênfase parece estar mais em identificar como esse ambiente constitui o indivíduo, mais do que compreender o processo histórico de formação desse ambiente (Andery \& Sério, 2003).

O fato de Skinner (1971) se referir a "arcabouço genético" diz respeito à concepção de que o comportamento também é determinado pela história da seleção natural da espécie (ver Skinner, 1981). A ausência de qualquer termo, sobre o assunto, no trecho de Lane (1981) não parece negar a condição apontada por Skinner (1971). Em outros trechos da autora aparecem indícios de que a dotação genéti$\mathrm{ca}$, relativa à influência de aspectos biológicos sobre o comportamento dos seres humanos, também é considerada por Lane (1984):

Porém o homem fala, pensa, aprende e ensina, transforma a natureza, o homem é cultura, é história. Este homem biológico não sobrevive por si e nem é uma espécie que se reproduz tal e qual, com variações decorrentes do clima, alimentação etc. (p.12)

A ênfase de Skinner (1971) no que acontece com o indivíduo assim que ele nasce, remete-se aos processos de aprendizagem que ocorrerão na interação desse indivíduo com o ambiente. $\mathrm{Na}$ obra de Lane (1981), encontram-se referências aos processos de aprendizagem operante:

As leis gerais da Psicologia dizem que se aprende quando reforçado, mas é a história do grupo ao qual o indivíduo pertence que dirá o que é reforçador ou o que é punitivo (...). Assim também aquilo que "deve ser apreendido" é determinado socialmente. (p.9)

Lane destaca nesse trecho que as práticas de reforçar e punir, que determinam quais são os comportamentos aprendidos em uma sociedade também são determinadas socialmente. Só seria possível compreender o porquê de serem essas contingências que estão presentes no mundo e não quaisquer outras, a partir da análise da história daquela sociedade, nesse sentido, ainda que exista uma aproximação clara entre a proposta de Lane e a de Skinner, parece que existe uma diferença na ênfase que cada autor dá às práticas de uma sociedade: Lane enfatiza os processos históricos de construção do ambiente social enquanto Skinner enfatiza as características do ambiente social que são responsáveis pela formação de um indivíduo. Outros analistas do comportamento têm trabalhado com a construção de ambientes sociais, principalmente aqueles preocupados com a evolução da cultura (Glenn, 2003; Malott, 1988; Tourinho, 2009).

Até o momento observa-se que em dois aspectos a proposta de Psicologia Social de Silvia Lane e a Análise do Comportamento teriam possibilidade de diálogo. A definição de Lane de que Psicologia Social estuda o comportamento no que ele é influenciado pelo ambiente social, mostra que o diálogo é possível visto que a Análise do Comportamento também estuda o comportamento humano levando em conta o efeito que a 
sociedade tem sobre ele. Desta forma o primeiro ponto de interface é o objeto de estudo, ambas têm como objeto de estudo o comportamento humano e levam em conta variáveis sociais que o influenciam.

O segundo ponto é a noção de que o ser humano constrói o ambiente em que vive. Essa preocupação aparece em trechos tanto de Silvia Lane quanto de Skinner. Diversos autores na Análise do Comportamento afirmam que é possível observar que na concepção skinneriana de ser humano, o ambiente que determina seus comportamentos é amplamente construído pelos próprios seres humanos (Andery 1993; Bissoli \& Micheletto, 2014; Gianfaldoni, 2005; Micheletto \& Sério, 1993; Nevin, 1992; Richelle, 1993). No trecho abaixo é possível identificar, além da determinação do comportamento pelo ambiente social, a construção desse ambiente:

O ambiente físico da maioria das pessoas é largamente feito pelo Homem. As superfícies em que uma pessoa anda, as paredes que a abrigam, as roupas que ela usa, muitas das comidas que ela come, as ferramentas que ela usa, os veículos com os quais se movem, a maioria das coisas que escuta e olha para são produtos humanos. O ambiente social é obviamente feito pelo homem - ele gera a língua que uma pessoa fala, os costumes que segue, e o comportamento que exibe com respeito a instituições éticas, religiosas, governamentais, econômicas, educacionais, e psicoterapêuticas que a controlam (Skinner, 1971, p.206).

Na obra de Lane (1981), a mesma noção aparece:

(...) a grande preocupação da Psicologia Social é conhecer como o homem se insere neste processo histórico, não apenas em como ele é determinado, mas principalmente, como ele se torna agente da história, ou seja, como ele pode transformar a sociedade em que vive (p.10).

\section{Influências de Skinner sobre a obra de Lane}

Em alguns trabalhos de Lane (1981; 1984, 1999 , 2002), foram encontrados trechos nos quais a autora cita e comenta o Behaviorismo Radical de B. F. Skinner. Lane (1984) apresentou, em sua discussão acerca da linguagem humana, uma referência à noção de comportamento verbal de Skinner:

Até o momento nos referimos apenas à linguagem, a ação de falar, porém não podemos esquecer que ela não é o único código de comunicação, a ponto de Skinner definir comportamento verbal como sendo 'todo aquele comportamento reforçado através da mediação de outras pessoas', e assim incluindo, além do falar, o escrever, os sinais, gestos, código Morse, e até os rituais. Esta definição é muito importante para ressalvar o caráter instrumental da linguagem, que se, de início, tinha que ser objetiva (coisa=significado), hoje adquiriu uma autonomia tal que permitiu mais uma divisão de trabalho manual versus a intelectual. (Lane, 1981, p.26-27)

A concepção de linguagem de Lane, reflete uma influência da noção de comportamento verbal de Skinner. Ambos ao estudarem os comportamentos de um sujeito como produto de interações com o meio social, defendem que a linguagem é um produto do meio social. É possível que a concepção de determinação dos comportamentos a partir da interação com o meio tenha possibilitado a aproximação entre as ideias de ambos os autores.

A própria autora, ao dialogar com a Análise do Comportamento, pontua o avanço que Skinner possibilitou. Segundo Lane (1984), partindo da proposta de Skinner, há a possibilidade de observar o ser humano como produto de suas relações sociais, entretanto, teceu uma crítica às concepções do autor:

Como exemplo, podemos citar Skinner, que, sem dúvida, causou uma revolução na psicologia, mas as condições histórico-sociais que o cercam impediram-no de dar um outro 
salto qualitativo. Ao superar o esquema S-R, chamando a atenção para a relação homem-ambiente, para o controle que este ambiente exerce sobre o comportamento; criticando o reducionismo biológico, permitiu a Skinner ver o homem como produto das suas relações sociais, porém não chega a ver estas relações como produzidas a partir da condição histórica de uma sociedade. Quando Skinner por meio da análise experimental do comportamento, detecta os controles sutis que, por meio das instituições, os homens exercem uns sobre os outros, e define leis de aprendizagem - e não podemos negar que reforços e punições de fato controlam comportamentos - temos uma descrição perfeita de um organismo que se transforma em função das consequências de sua ação, também a análise do autocontrole se aproxima do que consideramos consciência de si e o contracontrole descreve ações de um indivíduo em processo de conscientização social (...). A história individual é considerada enquanto história social que antecede e sucede a história do indivíduo. Nesta linha de raciocínio caberia questionar por que alguns comportamentos são reforçados e outros punidos dentro de um mesmo grupo social. Sem responder a estas questões, passamos a descrever o status quo como imutável e, mesmo querendo transformar o homem, como o próprio Skinner propõe, jamais o conseguiremos numa dimensão histórico-social. (Lane, 1984, p.14)

No trecho acima fica claro também um impasse. Lane (1984) fez uma crítica à proposta de Skinner no que diz respeito à limitação de se observar o ser humano como um produto de seu ambiente social, ainda que este o construa, sem que se compreenda como, historicamente, aquelas relações se produziram e o ambiente social em questão foi construído. No entanto, ainda que ao assumir a hipótese de que por impossibilidade de suas condições histórico-sociais Skinner não tenha produzido muito conhecimento sobre contingências ao longo da história que levaram a construção do ambiente social, não podemos dizer isso de todos os analistas do comportamento que o sucederam, ou foram seus contemporâneos (e.g. Guerin, 1992b, 2001;
Glenn, 2003; Tourinho, 2009), nem que o próprio Skinner não se preocupasse com uma transformação social que permitisse ao ser humano de fato exercer o controle de si mesmo e possibilitasse a mudança do futuro da cultura e da espécie (Bissoli \& Micheletto, 2014). Tal preocupação aparece no seguinte trecho de Skinner (1972):

Dois aspectos importantes, que geralmente se diz estarem em falta na visão científica de homem, na verdade são enfatizados por ela. Se o homem não tem liberdade de escolha, se não pode iniciar a ação que altera o curso causal de seu comportamento, então ele parece não ter controle sobre seu destino (...). O fato é, entretanto, que os homens controlam ambas as histórias genética e ambiental e nesse sentido, eles, de fato, controlam a si mesmos. Ciência e tecnologia estão preocupadas com a mudança do mundo em que os homens vivem, e mudanças são feitas precisamente devido a seus efeitos no comportamento humano. Nós temos atingido um estágio, longe de um beco sem saída, no qual o homem pode determinar seu futuro com uma ordem inteiramente nova de efetividade (...). Os homens controlam a si mesmos ao controlar o mundo no qual vivem. Eles fazem isso tanto quando exercem autocontrole, quanto quando eles realizam mudanças em sua cultura que alteram a conduta de outros. (p. 56)

A partir desse trecho é possível afirmar que Skinner entende o ser humano como produto e produtor não só de si, mas do mundo que o cerca e por decorrência do ambiente social que o determina. Condição que Lane (1984) considera crucial para que o conhecimento psicológico não favoreça a manutenção do status quo. Como apontou a autora:

Se o homem não for visto como produto e produtor, não só de sua história pessoal, mas da história de sua sociedade, a psicologia estará apenas reproduzindo as condições necessárias para impedir a emergência das contradições e a transformação social. (p.15)

Na concepção skinneriana, a possibilidade de os seres humanos darem direção a suas vidas, pas- 
saria pela possibilidade de um planejamento cultural que levasse em conta as consequências remotas de seus comportamentos no futuro. Para isto, é preciso que os seres humanos planejem seus ambientes de forma a favorecer comportamentos para o bem e sobrevivência dos outros membros da cultura, e não só para si. Assim, aumentando a possibilidade de sobrevivência dos outros no futuro, passam a aumentar as chances de sobrevivência da cultura que esses praticam bem como da espécie humana, da qual fazem parte (Bissoli \& Micheletto, 2014). Para tanto, analisar como os sistemas vigentes influenciam o comportamento humano, que consequências essas influências e comportamentos terão para o futuro e como podemos mudá-las se faz de extrema importância.

Até o momento, foi apontado que a Psicologia Social proposta por Lane $(1981,1984)$ considera que o ser humano é determinado pela sociedade em que está inserido, mas se volta para possibilidade do ser humano agir nessa determinação, ser um agente em sua história, e não simplesmente um produto dela que tende a manter um status quo onde poucos têm acesso a muitos recursos e muitos a pouquíssimos recursos produzidos pelos próprios seres humanos em seus trabalhos coletivos. Para Lane, (1984) o enfoque é a consciência das contradições históricas que permitem aos indivíduos agirem como um grupo visando a mudança e superação dessas contradições, ou seja, ocorra uma transformação social:

A consciência da reprodução ideológica inerente aos papéis socialmente definidos permite aos indivíduos no grupo superarem suas individualidades e se conscientizarem das condições históricas comuns aos membros do grupo, levando-os a um processo de identificação das atividades conjuntas que caracterizam o grupo como unidade (...) consciência de classe, quando o grupo se percebe inserido no processo de produção material de sua vida e percebe as contradições geradas historicamente, levando-o a atividades que visam à superação das contradições presentes no seu cotidiano, torna-se um grupo-sujeito da transformação social. (Lane, 1984, p.17).
Até o momento foi apresentado que duas concepções aproximam as ideias da Psicologia Social de Lane e a Análise do Comportamento: (a) a noção de ser humano construído a partir de suas relações com o ambiente social e; (b) a noção de que os seres humanos constroem a maior parte do ambiente em que vivem. Outro ponto de diálogo é a noção de transformação social de Lane e da Análise do Comportamento, além da aplicação dos princípios comportamentais à problemas sociais.

\section{Análise do Comportamento e Transformação Social}

Ao longo da história, a Análise do Comportamento se constituiu enquanto uma disciplina que apresenta um objeto de estudo bem estabelecido, compreende um conjunto de princípios, técnicas e métodos de pesquisa próprios e apresenta uma grande quantidade de dados empíricos embasando seus princípios (Lamal, 1991; Michael, 1984). Ao longo dessa história, que envolveu tanto a pesquisa quanto a prática, começou a surgir uma necessidade de discutir princípios e técnicas que levem em conta a transformação social (Andery, 2011; Lamal, 1991).

A Análise do Comportamento começou em laboratório com pesquisas com animais não-humanos na década de 1930. Logo, tornou-se importante estender os princípios comportamentais advindos do laboratório para o comportamento humano e iniciou-se um programa de pesquisas que eram feitas em laboratórios. As respostas medidas eram simples, como pressão à barra ou pressão de botões, e existia uma predominância de estudos com comportamentos em situações não sociais (Michael, 1984), o primeiro relato de pesquisa, em Análise do Comportamento feito com indivíduos em interação social datou de 1956 (Azrin \& Lindsley,1956).

Também na década de 1950, se iniciaram as primeiras aplicações da Análise do Comportamento aos problemas humanos. Os analistas do comportamento trabalhavam principalmente no laboratório, desenvolvendo princípios básicos, até que surgiram demandas de aplicação dos princípios da Análise do Comportamento em instituições sociais como escolas, prisões, hospitais, reformatórios ou instituições de saúde mental (Kazdin, 1978). Ainda que 
houvesse uma preocupação com o estabelecimento de critérios para a escolha do comportamento que será alvo de intervenção (Baer, Wolf, \& Risley, 1968; 1987; Wolf, 1978; Kennedy, 1993), diversas críticas foram e têm sido feitas aos focos de intervenção dos analistas do comportamento (Fink, 2014; Holland, 1975; 1978a; Kunkel, 1987). Essas críticas apontam que os comportamentos selecionados para intervenção estão mais relacionados com a manutenção de contingências que mantêm o status quo do que com a modificação dessas contingências.

Baer, Wolf e Risley (1968) na primeira edição do Journal of Applied Behavior Analysis, um dos mais importantes periódicos da Análise do Comportamento que apresenta relatos de pesquisas de aplicação de princípios comportamentais a problemas humanos, definiram critérios para intervenções comportamentais. Os critérios para a escolha do comportamento, aparentemente incluía uma preocupação com o papel da intervenção analítico-comportamental sobre a sociedade: "Na aplicação comportamental, o comportamento, estímulo e/ou organismo sob estudo é escolhido devido à sua importância para o homem e sua sociedade, ao invés de sua importância teórica" (Baer, Wolf, \& Risley, 1968, p. 92). No entanto, algumas questões permaneceram abertas: (a) o que significa essa importância para a sociedade?; (b) qual camada da sociedade os autores estão falando (a comunidade que o indivíduo cujos comportamentos são foco de intervenção, os contratantes do serviço, as pessoas que estão no poder)?

Posteriormente, Analistas do Comportamento preocupados com essas questões trabalharam no estabelecimento de critérios para a Validação Social do comportamento escolhido (Wolf, 1978; Bear, Wolf \& Risley, 1987). No entanto, a discussão não se encerrou, ainda com um número especial do Journal of Applied Behavior Analysis sendo publicado em 1991 (para críticas acerca do conceito e dos procedimentos de Validação Social ver Adkins, 1997; Fawcett, 1991; Kennedy, 1993).

Baer, Wolf e Rilsey (1968) também arriscaram uma previsão do impacto que as intervenções analítico-comportamentais teriam sobre a sociedade: "Melhores aplicações, assim é esperado, levarão a um melhor estado da sociedade, na medida em que os comportamentos de seus membros possam contribuir para o bem da sociedade" (p. 91). Novas questões podem surgir: (a) o que significa um melhor estado da sociedade?; (b) o que significa bem da sociedade?

Questões como essas levaram uma parcela de analistas de comportamento a criticarem as práticas relacionadas com a aplicação da Análise do Comportamento a problemas humanos. Holland $(1975 ; 1978 a)$, por exemplo, apontou que os comportamentos escolhidos para intervenção reproduziam a estrutura social. Segundo o autor, os analistas do comportamento que começaram a trabalhar com a aplicação dos princípios comportamentais a prisões, por exemplo, "algumas vezes tratam prisioneiros como se estivessem desajustados e podem ser 'consertados' em um sistema de modificação do comportamento (...) e de alguma forma esperavam que aquelas contingências que modelaram o comportamento criminoso originalmente não exercerão mais controle" (Holland, 1978a, p. 170).

Tendo em vista essas críticas, o autor propôs a análise de contingências sociais como um objetivo dos analistas do comportamento e que a Análise do Comportamento já disporia das ferramentas para tal realizar análise: "a análise do comportamento provê os meios para analisar a estrutura, o sistema e as formas de controle social" (Holland, 1978a, p. 163). Holland (1978a) ainda apontou que a transformação social viria a partir do ensino de métodos de análise de contingências a fim de evidenciar as contingências relacionadas com a opressão social:

\begin{abstract}
Nossas velhas práticas, úteis quando abraçamos a culpabilização ou glorificação de vítimas, devem ser modificadas. Algumas novas metodologias são necessárias. Sugiro que precisamos trabalhar com pessoas em todas as nossas instituições sociais analisando as contingências que as oprimem. Trazemos a esta empreitada certos conhecimentos e habilidades especializados no uso de dados; eles trazem uma experiência direta com as contingências do dia-a-dia. (Holland, 1978a, p. 172)
\end{abstract}

Outros autores, como Sigrid Glenn (1991) também apontaram para a importância de uma compreensão dos sistemas sociais e apontaram para a necessidade de compreensão dos processos de transformação social: 
Muitos de nós que reconhecem nossas próprias contribuições para os problemas da sociedade também reconhecem que mesmo se nós nos comportarmos de forma diferente, os problemas sociais não serão atenuados até que o comportamento de muitas outras pessoas também mude. Em resumo, nós estamos presos em um grande sistema que parece impenetrável a nossos pequenos esforços. Ainda assim, mudanças dramáticas acontecem - em sociedades e em indivíduos. Precisamos compreender como isso acontece. Em outras palavras, nós temos que compreender como o comportamento individual funciona, como sistemas sociais funcionam, e como eles estão relacionados. (Glenn, 1991, p. 39)

A preocupação de Glenn (1991) é em uma medida semelhante à de Holland (1978a) no que diz respeito à necessidade de compreensão de sistemas sociais, no entanto, para ela ainda seriam necessárias ferramentas para a compreensão desses sistemas sociais e para Holland (1978a) a Análise do Comportamento já apresentaria as ferramentas necessárias para a análise dos sistemas sociais. A proposta de ambos ainda é diferente no que diz respeito à maneira que seria possível realizar uma intervenção analítico-comportamental tendo em vista questões sociais:

\section{Então podemos começar a especificar as ações mais prováveis de dissuadir e reverter as tendên- cias calamitosas e as condições sob as quais os in- divíduos devem agir. Ao arranjar tais condições, juristas e juízes, empregadores e empregados, educadores, diretores executivos e pais podem melhorar nossas chances de evitar as ameaças que nos defrontam. (Glenn, 1991, p. 39).}

Para Glenn (1991) o papel do analista do comportamento seria o de especificar ações de como os indivíduos deveriam agir para modificar a sociedade. Não há nessa proposta da autora uma preocupação explícita com a desigualdade social como aparece na obra de Holland (1978a) que estaria mais intrinsecamente relacionado com as propostas de Lane $(1981,1984)$. Em textos posteriores, Glenn (2004; Malott \& Glenn, 2006) apresenta a possibi- lidade de intervenção em sistemas sociais amplos baseada em duas ferramentas teóricas que propôs ao longo de sua obra: metacontingências e macrocontingências.

Uma macrocontingência é uma ferramenta de análise para identificação de problemas sociais amplos. Ela descreve a relação entre contingências comportamentais de indivíduos diferentes que não têm necessariamente uma relação entre si, mas que em conjunto geram um efeito cumulativo que não seria possível se esses comportamentos não ocorressem (Malott \& Glenn, 2006). Um exemplo, é a poluição de uma cidade que é o efeito cumulativo de comportamentos de diferentes indivíduos que não têm relação entre si, por exemplo, os relacionados com veículos automotivos, indústrias ou utilização de lixo.

Uma metacontingência descreve uma relação entre um conjunto de contingências comportamentais que se entrelaçam (indivíduos em interação) e geram um efeito que não poderia ser produzido sem esse entrelaçamento. Essa interação e esse produto recorrem ao longo do tempo quando produzem uma consequência ambiental, chamada de consequência cultural (Glenn, 1988; 1991; 2003; 2004). Essa recorrência é possível inclusive com pessoas diferentes e ao longo de gerações. Dessa maneira, é possível compreender a estrutura de sistemas sociais que permanecem intactos mesmo com pessoas diferentes.

O próprio Skinner apresentou ao longo de sua obra uma preocupação com a transformação social, de uma maneira semelhante à de Glenn. Ainda que ao longo de sua obra sua noção de sociedade tenha mudado: inicialmente, Skinner, enxergava a sociedade como uma coleção de comportamentos, posteriormente passou a enxergar a sociedade como um conjunto de relações que geravam um produto diferente do obtido por pessoas se comportando individualmente (Andery \& Sério, 2003). Além disso, ao longo de sua obra, o autor passou a enxergar a sociedade e a cultura como um produto histórico e a buscar uma maneira de compreender a transformação das sociedades e das culturas utilizando o termo evolução cultural (Skinner, 1981; 1989).

Ao longo do desenvolvimento da Análise do Comportamento, enquanto uma disciplina teórica e prática, a cultura e sociedade passaram a serem compreendidas como unidades que se transformam 
e seria necessária a busca das variáveis responsáveis por essas transformações (Andery, 2011). Então, as questões levantadas por Lane $(1981 ; 1984)$ acerca da necessidade de compreensão da construção do ambiente social aparecem como uma preocupação dos analistas do comportamento, tendo em vista que a compreensão de processos de transformação de sistemas sociais traria respostas tanto teóricas quanto práticas (Andery, 2011).

\section{A questão do método de estudo}

O método de pesquisa proposto por Lane é a pesquisa-ação. Uma parte importante desse método consiste na observação participante, um método de pesquisa tradicional de ciências sociais como Sociologia e Antropologia. O pesquisador entra em contato com uma dada comunidade e lá viverá seus costumes, a partir dessa vivência ele poderá interpretar os fenômenos que observou. Segundo Lane (1984):

A partir de um enfoque fundamentalmente interdisciplinar, o pesquisador-produto-histórico parte de uma visão de mundo e do homem necessariamente comprometida e neste sentido, não há possibilidade de se gerar um conhecimento "neutro", nem um conhecimento do outro que não interfira na sua existência. Pesquisador e pesquisado se definem por relações sociais que tanto podem ser reprodutoras como podem ser transformadoras das condições sociais onde ambos se inserem; desta forma, conscientes ou não, sempre a pesquisa implica intervenção, ação de uns sobre outros. A pesquisa em si é uma prática social onde pesquisador e pesquisando se apresentam enquanto subjetividades que se materializam nas relações desenvolvidas, e onde os papéis se confundem e se alternam, ambos objetos de análise e, portanto, descritos empiricamente. Esta relação - objeto de análise - é captada em seu movimento, o que implica, necessariamente, pesquisa-ação. (p. 18)

Enquanto estuda uma dada comunidade, o pesquisador estará também intervindo. Como a comunidade é formada por relações, segundo Lane, o pesquisador só de estar presente já interferiria no fenômeno, não produziria um conhecimento "neutro" no sentido de que o objeto de estudo, necessariamente influencia e seria influenciado pelo sujeito (o pesquisador).

Os métodos de pesquisa tradicionais da Análise do Comportamento envolvem na maioria dos casos experimentação, sobretudo delineamento de sujeito único (o sujeito em comparação com sua própria história - Sampaio et al, 2010; Sidman, 1960; Skinner, 1956), e em alguns casos observação sistemática, ou em outros, análise de dados empíricos provenientes de outras fontes (dados coletados por outras pessoas ou instituições, documentos, etc.). As questões são sempre relacionadas com o efeito de uma variável sobre outra.

Pierce (1991) apontou três maneiras pelas quais a Análise do Comportamento poderia estudar fenômenos sociais complexos: (a) observação e descrição do comportamento das pessoas (semelhante à etnografia); (b) quasi-experimentação (e.g. Sampaio, 2008), que consiste na análise de fenômenos históricos e a identificação de variáveis que alteraram o fenômeno ao longo da história e; (c) experimentação em pequenos grupos. Além dos métodos propostos por Pierce (1991), analistas do comportamento tem realizado estudos interpretativos de fenômenos sociais complexos (e.g. Angelo, Pergher \& Martone, 2010; Rakos, 1993; Todorov, 1987).

Experimentos com pequenos grupos têm sido conduzidos sistematicamente por diferentes grupos de pesquisa no Brasil. A maioria desses experimentos busca investigar processos relacionados com as transformações culturais em metacontingências ou macrocontingências (Hosoya \& Tourinho, 2016; Saconatto e Andery, 2013; Ortu, Becker, Woelz \& Gleen, 2012; Vich, Andery \& Glenn, 2009). A experimentação em pequenos grupos também tem sido feita na Psicologia Social, no entanto, não na Psicologia Social brasileira, mas sim na Psicologia Social Cognitivista.

Lane criticava fortemente a Psicologia Social Cognitivista, tendo em vista as declarações abertas de que possuíam uma ciência neutra e propondo intervenções verticais (e.g. Rodrigues \& Hutz, 1989), nas quais a ciência básica forneceria uma tipificação dos indivíduos e os cientistas prescreveriam o que 
deveria ser feito pela comunidade. Os experimentos sobre metacontingências ou macrocontingências não tentam descrever características humanas ou tipificar os sujeitos a partir de escolhas ou emoções que sentem diante de estímulos. A experimentação com pequenos grupos em Análise do Comportamento é uma estratégia para observar fenômenos sociais em ambiente controlado. A ideia é propiciar um aprimoramento das ferramentas teóricas que os analistas do comportamento têm utilizado para estudar fenômenos sociais amplos. Esses conceitos são utilizados para descrever processos em nível cultural e não tipificar um conteúdo cultural específico (ver Glenn \& Malagodi, 1991, para uma discussão acerca da diferença entre processo e conteúdo).

A questão de como essas ferramentas teóricas serão utilizadas para a transformação social passa por outros fatores relacionados à história de vida daqueles que proporão as transformações sociais. Um exemplo disso, é a diferença de propostas para a transformação social de Holland (1975; 1978a) e Glenn (1991).

Poucos trabalhos assumem a tarefa de descrever contingências às quais o pesquisador foi exposto de uma maneira semelhante à pesquisa-ação. Skinner (1956), ainda que não estivesse preocupado com fenômenos sociais amplos, descreveu as contingências responsáveis pelas formulações experimentais e teóricas que o levaram à proposição da Análise do Comportamento. Nogueira e Sampaio (2016) descreveu as contingências presentes em um jogo online enquanto jogava. Nesse trabalho, a descrição das contingências foi feita por alguém que estava submetido às contingências e que estava em uma posição em que as contingências que descrevia eram alteradas na medida em que se comportava. Holland (1978b) conviveu, trabalhou, e morou com um grupo enquanto analisava as contingências vigentes. Esse grupo, nomeado Brigada Venceremos, era um mutirão feito em Cuba para construir habitações. A partir dessa experiência, Holland (1978b) produziu um estudo de caso.

Além disso, Guerin $(2003 ; 2005)$ propôs intervenções comportamentais baseadas em observação participante e análise do discurso das pessoas que vivem na comunidade. Essa proposta de Guerin (2003; 2005) assemelha-se à proposta de pesquisa-ação de Silva Lane (1984).

\section{Conclusão}

Em resumo, a Psicologia Social de Silvia Lane, ainda que apresente diferenças importantes parece ser uma fonte interessante de informações para analistas do comportamento que busquem estabelecer um diálogo com outros autores, principalmente autores que estudem propostas para transformação social, o que tem sido uma preocupação crescente entre os analistas do comportamento. As teorias mostram-se compatíveis no que diz respeito à concepção de ser humano (ambos consideram que o indivíduo se constrói em sua interação com o meio social e durante esse processo constrói também seu ambiente social).

A proposta de interface entre a Psicologia Social de Lane e a Análise do Comportamento pode se beneficiar de estudos epistemológicos que considerem a noção materialista de ambas as teorias, bem como a proposta dialética de Lane (para uma tentativa de aproximação entre dialética e o modelo selecionista da Análise do Comportamento ver Andery \& Sério, 2003). Outra questão que pode contribuir para o avanço da interface é um estudo mais aprofundado da visão de Silva Lane $(1999,2002)$ acerca da produção de conhecimento no pensamento skinneriano.

No presente ensaio apesar de discutidas possíveis aproximações metodológicas entre a pesquisa-ação tal como descrita por Lane (1984) e o trabalho de Guerin $(2003,2005)$, a maior parte das pesquisas de análise do comportamento que estudam fenômenos sociais não se assemelham como o método proposto por Lane (1984). Assim, um avanço das discussões sobre a possibilidade de interface pode contribuir tanto para o desenvolvimento de novas propostas metodológicas para a Psicologia Social quanto para analistas do comportamento que estudam fenômenos sociais. Além disso, uma leitura cuidadosa da Psicologia Social brasileira proposta por Silvia Lane pode contribuir para as discussões teóricas, éticas e metodológicas da Análise do Comportamento. 


\section{Referências}

Adkins, V. K. (1997). Social validity and naturalistic ethics: Wolf and Quine. Behavior and Social Issues, 7, 153-157.

Andery, M. A. (1993). Uma Sociedade Voltada para o Futuro. Temas em Psicologia, 2, 23-30.

Andery, M. A. P. A. (2011). Comportamento e cultura na perspectiva da Análise do Comportamento. Perspectivas em Análise do Comportamento, 2, 203-217.

Andery, M. A., \& Sério, T. M. (2003). Metacontingencias y dialéctica: Son incompatibles? Revista Latinoamericana de Psicologia, 35, 273-280.

Angelo, H. V. B. R.; Pergher, N. K. \& Martone, R. C. (2010). O papel da mídia na construção da imagem de um candidato à disputa presidencial. Em: M. M. C. Hübner; M. R. Garcia; P. R. Abreu \& E. N. Cillo.Sobre Comportamento e Cognição (pp. 91-102). Santo André: ESETec.

Azrin, N. H., \& Lindsley, O. R. (1956). The reinforcement of cooperation between children. The Journal of Abnormal and Social Psychology, 52, 100-102.

Baer, D. M., Wolf, M. M., \& Risley, T. R. (1968). Some current dimensions of applied behavior analysis. Journal of Applied Behavior Analysis, 1, 91-97.

Baer, D. M., Wolf, M. M., \& Risley, T. R. (1987). Some still-current dimensions of applied behavior analysis. Journal of Applied Behavior Analysis, 20, 313-327.

Bissoli, E. B. \& Micheletto, N. (2014). O ser humano capaz de dar direção à sua vida. In: N. B. Borges; L. G. Aureliano \& J. L. Leonardi (Orgs.) Comportamento em Foco, Vol.4 (pp. 231-250). São Paulo: Associação Brasileira de Psicologia e Medicina Comportamental

Fawcett, S. B. (1991). Social validity: A note on methodology. Journal of Applied Behavior Analysis, 24, 235-239.

Fink, J. D. (2014). O compromisso social dos analistas do comportamento: caracterização e exame de publicações em periódicos brasileiros da área. Dissertação de Mestrado. Programa de Estudos Pós-Graduados em Psicologia Experimental: Análise do Comportamento, Pontifícia Universidade Católica de São Paulo.
Gianfaldoni, M. H. T. A. (2005). A Educação como Prática Cultural Ética: uma leitura possível das propostas de B. F. Skinner. Tese de Doutorado, Pontifícia Universidade Católica, São Paulo.

Glenn, S. S. (1988). Contingencies and metacontingencies: Toward a synthesis of behavior analysis and cultural materialism. The Behavior Analyst, $11,161-179$.

Glenn, S. S. (1991). Contingencies and metacontingencies: Relations among behavioral, cultural, and biological evolution. Em P. A. Lamal (Ed.), Behavioral analysis of societies and cultural practices (pp. 39-73). New York: Hemisphere.

Glenn, S. S. (2003). Operant contingencies and the origins of cultures. Em K. A. Lattal \& P. N. Chase (Eds.), Behavior theory and philosophy (pp. 223-242). New York: Klewer Academic/ Plenum.

Glenn, S. S. (2004). Individual behavior, culture, and social change. The Behavior Analyst, 27, 133-151.

Guerin, B. (1992). Behavior Analysis and Social Psychology: a review of Lana's assumptions of Social Psychology. Journal of the Experimental Analysis of Behavior, 58, 589-604.

Guerin, B. (2001). Individuals as social relationships: 18 ways that acting alone can be thought of as social behavior. Review of General Psychology, 5, 406 - 428.

Guerin, B. (2003). Combating prejudice and racism: New interventions from a functional analysis of racist language. Journal of Community and Applied Social Psychology, 13, 29-45.

Guerin, B. (2005). Handbook of Interventions for Changing People and Communities. Reno, NV: Context Press.

Guerin, B. (2009). Análise do Comportamento e construção social do conhecimento (Trads. H. V. B. R. Angelo, R. C. Martone \& C. M. de Melo). Revista Brasileira de Análise do Comportamento, 5, 117-137. Publicado originalmente em 1992.

Holland, J. G. (1975) Behavior modification for prisoners, patients, and other people as a prescription for the planned society. Mexican Journal Analysis of Behavior, 1, 81-95 
Holland, J. G. (1978a) Behaviorism part of the problem or of the solution? Journal of Applied Behavior Analysis, 11, 163-174.

Holland, J. G. (1978b). To Cuba with the venceremos brigade. Behaviorists for Social Action Journal, 1, 21-28.

Hosoya, N. M. S., \& Tourinho, E. Z. (2016). Efeitos de interações verbais na seleção e manutenção de contingências comportamentais entrelaçadas. Acta Comportamentalia: Revista Latina de Análisis del Comportamiento, 24, p. 331-345.

Kazdin, A. E. (1978). History of Behavior Modification: Experimental foundations of contemporary research. Baltimore: University Park Press.

Kennedy, C. H. (1993). Trends in the Measurement of Social Validity. The Behavior Analyst, 15, 147-156.

Kunkel, J. H. (1987). The future of JABA: A comment. Journal of Applied Behavior Analysis, 20, 329-333.

Kunkel, J. H. (1997). Three contributions of social psychology to the analysis of the behavior-consequence linkage. The Psychological Record, 47, 201-220.

Lamal, P.A. (1991) - Behavior analysis of societies and cultural practices. In: P.A. Lamal (Ed.), Behavior analysis of societies and cultural practices (3-12). New York: Hemisphere Publishing Corporation.

Lana, R. E. (1994). Social history and the behavioral repertoire. Journal of the Experimental Analysis of Behavior, 62, 315-322.

Lane, S. T. M. (1981). O que é Psicologia Social? São Paulo, SP, Editora Brasiliense.

Lane, S. T. M. (1984). A psicologia social e uma nova concepção do homem para a psicologia. Em Lane, S. T. M. e Codo, W. (Orgs.) Psicologia Social: o homem em movimento (pp. 10-19). São Paulo, SP, Editora Brasiliense.

Lane, S. T. M. (1999). Ideology and consciousness. Theory \& Psychology, 9(3), 367-378.

Lane, S. T. M. (2002). A dialética da subjetividade versus objetividade. Em: O. Furtado \& F. G. Rey (Orgs.) Por uma epistemologia da subjetividade: Um debate entre a teoria sócio-histórica e a teoria das representações sociais, (11-17). São Paulo: Casa do Psicólogo.
Malott, M. E. \& Glenn, S. S. (2006). Targets of Intervention in Cultural and Behavioral Change. Behavior and Social Issues, 15, 31-56.

Martin-Baró, I. (1996). O papel do psicólogo. Estudos de Psicologia, 2, 7-27.

Michael, J. (1984). Verbal behavior. Journal of the Experimental Analysis of Behavior, 42, 363-376.

Micheletto, N. \& Sério, T. M. A. P. (1993). Homem: Objeto ou Sujeito para Skinner?. Temas em Psicologia, 2, 1-9.

Nevin, J. A. (1992). B.F. SKINNER: On Behalf of the future. Behavior and Social Issues, 2, 83-88.

Nogueira, A. L. D. D., \& Sampaio, A. A. S. (2016). Análise de Fenômenos Sociais em um Jogo On-Line para Múltiplos Jogadores. Revista Perspectivas em Análise do Comportamento, 7, 59-69.

Ortu, D., Becker, A. M., Woelz, T. A. R. \& Glenn, S. S. (2012). An iterated four-player prisoner's dilemma game with an external selecting agent: a metacontingency experiment. Revista Latinoamericana de Psicología, 44, 111-120.

Pierce, W. D. (1991). Culture and society: The role of behavioral analysis. Em P. A. Lamal, Behavioral analysis of societies and cultural practices (pp. 13-37). New York: Hemisphere.

Richelle, M. N. (1993). B.F. Skinner a reappraisal. Hillsdale, USA: Lawrence Erlba Associate Publishers.

Rodrigues, A., \& Hutz, C. S. (1989). A psicologia social nas vésperas de seu primeiro centenário. II Simpósio Brasileiro de Pesquisa e Intercâmbio Científico, 117-136.

Rakos, R. F. (1993). Propaganda as stimulus control: The case of the Iraqi invasion of Kuwait. Behavior and Social Issues, 3, p. $35-62$.

Rosa, E. Z. \& Andriani, A. G. (2002). Psicologia sócio-histórica: uma tentativa de sistematização epistemológica e epistemológica. Em E. M. P. Kahhale (Org.) A diversidade da Psicologia: uma construção teórica (pp. 259 - 288). São Paulo: Cortez.

Sawaia, B. B. (2014). Transformação social: um objeto pertinente à Psicologia Social? Psicologia \& Sociedade, 26, 4-17.

Skinner, B. F. (1953). Science and human behavior. New York: The Free Press. 
Skinner, B. F. (1956). A case history in scientific method. American Psychologist, 11, 221-33.

Skinner, B. F. (1971). Beyond Freedom and Dignity. New York, NY Alfred A. Knopf.

Skinner, B. F. (1972). Creating the creative artist. In B. F. Skinner. Cumulative record, $3^{a}$ ed, (pp. 333344). New York, NY: Appleton-Century-Crofts.

Skinner, B. F. (1978). Human behavior and democracy. Em B. F. Skinner (Org.), Reflections on behaviorism and society (pp. 3-15). Englewood Cliffs, NJ: PrenticeHall.

Skinner, B. F. (1981). Selection by consequences. Science, 213, 501-504.

Skinner, B. F. (1989). Recent issues in the analysis of behavior. Columbus, $\mathrm{OH}$ : Merril.

Todorov, J. C. (1987). A Constituição como metacontingência. Psicologia: Ciência e Profissão, 7, 9-13.

Tourinho, E. Z. (2009). Subjetividade e relações comportamentais. São Paulo: Paradigma.

Vichi, C., Andery, M. A. P. A. \& Glenn, S. S. (2009). A Metacontingency Experiment: The Effects of Contingent Consequences on Patterns of Interlocking Contingencies of Reinforcement. Behavior and Social Issues, 18, 41-5.

Wolf, M. M. (1978). Social validity: the case for subjective measurement or how applied behavior analysis is finding its heart. Journal of Applied Behavior Analysis, 11, 203-214.

\section{Informações do Artigo}

\section{Histórico do artigo:}

Submetido em: 13/02/2016

Primeira decisão editorial: 09/08/2016

Aceito em: 14/11/2016

Editor Associado: Felipe Leite 